\title{
Investigation and analysis of the linkage mechanism and whole process cost of livestock manure organic fertilizer
}

\author{
Shanshan Dong ${ }^{1,2}$, Bin Sui ${ }^{2 *}$, Yujun Shen ${ }^{1,2}$, Haibo Meng ${ }^{1,2}$, Lixin Zhao ${ }^{1,3}$, \\ J ingtao Ding ${ }^{1,2}$, Haibin Zhou ${ }^{1,2}, X_{i}$ Zhang $^{1,2}$, Hongsheng Cheng ${ }^{1,2}$, \\ J ian Wang ${ }^{1,2}$, Ran $\mathrm{Li}^{1,2}$, Liqiu Song ${ }^{1,2}$, Pengxiang $\mathrm{Xu}^{1,2}$, Ji Li ${ }^{4}$ \\ (1. Institute of Energy and Environmental Protection, Academy of Agricultural Planning and Engineering, \\ Ministry of Agriculture and Rural Affairs, Beijing 100125, China; \\ 2. Key Laboratory of Technologies and Models for Cyclic Utilization from Agricultural Resources, \\ Ministry of Agriculture and Rural Affairs, Beijing 100125, China; \\ 3. Key Laboratory of Energy Resource Utilization from Agriculture Waste, Ministry of Agriculture and Rural Affairs, Beijing 100125, China; \\ 4. College of Resources and Environmental Sciences, China Agricultural University, Beijing 100193, China)
}

\begin{abstract}
In recent years, the utilization of manure resources for livestock and poultry farming has attracted a widespread attention, and manure resources utilization models suitable for different regional characteristics have formed gradually. Among them, the production of organic fertilizer from animal manure is a vital utilization method. However, there are still some problems such as high production costs, difficult sales, and the unwillingness of farmers to use organic fertilizers which have affected the breeding cycle and the sustainability of manure treatment in livestock and poultry breeding. This article selected 371 organic fertilizer plants, related farms and farmers in China, focusing on the main links of the entire process of livestock manure-organic fertilizer-farm application, and studied the mode of animal manure collection by organic fertilizer plants. The costs of organic fertilizer production and farmland application were discussed. Moreover, suggestions were made for the promotion and implementation of large-scale organic fertilizers to make good utilization of manure resources in livestock and poultry farming.
\end{abstract}

Keywords: livestock manure, organic fertilizer, compost, production cost, application cost DOI: $10.25165 /$ j.jjabe.20201302.

Citation: Dong S S, Sui B, Shen Y J, Meng H B, Zhao L X, Ding J T, et al. Investigation and analysis of the linkage mechanism and whole process cost of livestock manure organic fertilizer. Int J Agric \& Biol Eng, 2020; 13(2): $223-227$.

\section{Introduction}

As an essential means of production, fertilizer has an

Received date: 2020-01-06 Accepted date: 2020-03-23

Biographies: Shanshan Dong, Engineer, research interests: cyclic utilization from agricultural resources, Email: dongshanshan@aape.org.cn; Yujun Shen, Senior Engineer, research interests: cyclic utilization from agricultural resources, Email: shenyujun@aape.org.cn; Haibo Meng, Professor, research interests: cyclic utilization from agricultural resources, Email: menghaibo@aape.org.cn; Lixin Zhao, Professor, research interests: energy resource utilization of agricultural wastes, Email: zhaolixin@aape.org.cn; Jingtao Ding, Senior Engineer, research interests: cyclic utilization from agricultural resources, Email: dingjingtao@aape.org.cn; Haibin Zhou, Senior Engineer, research interests: treatment and utilization of agricultural wastes, Email: zhouhaibin@aape.org.cn; Xi Zhang, Senior Engineer, research interests: fertilizer utilization of agricultural wastes, Email: zhangxi@aape.org.cn; Hongsheng Cheng, Senior Engineer, research interests: fertilizer utilization of agricultural wastes, Email: chenghongsheng@aape.org.cn; Jian Wang, Engineer, research interests: cyclic utilization from agricultural resources, Email: wangjian@aape.org.cn; Ran Li, Assistant Engineer, research interests: fertilizer utilization of agricultural wastes, Email: liran@aape.org.cn; Liqiu Song, Senior Engineer, research interests: cyclic utilization from agricultural resources, Email: songliqiu@aape.org.cn; Pengxiang Xu, Senior Engineer, research interests: organic waste compost and resource utilization, Email: songliqiu@aape.org.cn; Ji Li, Professor, research interests: organic waste compost and resource utilization, Email: liji@cau.edu.cn.

*Corresponding author: Bin Sui, Professor, research interests: agricultural engineering management, agricultural and rural construction and cyclic utilization of agricultural resources. No.41, Maizidian Street, Chaoyang District, Beijing 100125, China. Tel: +86-10-59197281, Email: suibin@agri.gov.cn. irreplaceable role in promoting the development of the agricultural output, however, there are some problems such as excessive supplementation of chemical fertilizers, blind replacement, undue emphasis on the substitution of synthetic fertilizers for crops, and the impact on soil quality. Contradictions such as the reduction of excess fertilizer, food safety, depletion of resources, and environmental pollution have become increasingly prominent. Organic fertilizers have received widespread attention due to their characteristics of improving soil fertility and environmental friendliness $^{[1-4]}$.

At present, the raw materials for organic fertilizer production mainly include agricultural production and processing waste, urban domestic waste, and municipal sludge ${ }^{[5]}$. According to statistics, about $3.80 \times 10^{10} \mathrm{t}$ of various types of livestock and poultry manure and $1.00 \times 10^{9} \mathrm{t}$ of crop stalks are produced each year, which can provide about $8.00 \times 10^{8} \mathrm{t}$ of organic matter and $7.30 \times 10^{8} \mathrm{t}$ of nitrogen. However, the actual utilization is less than $40 \%{ }^{[6,7]}$. Among the existing organic fertilizers, the organic manure produced by livestock and poultry manures provided with higher organic matter and nitrogen, phosphorus, potassium, and various trace element substances, which can provide nutrients for crop growth and improve fertility as the market favors ${ }^{[8,9]}$. According to the literature review, the scale of fouling produced by large-scale livestock and poultry manure in China was $3.83 \times 10^{9}$ t, of which fresh manure was $6.36 \times 10^{8}$ t, urine was $5.65 \times 10^{8} \mathrm{t}$, and sewage was $2.63 \times 10^{9} \mathrm{t}$ by 2015 . From the perspective of accumulation, 
the nitrogen and phosphorus production in livestock and poultry manures were $1.23 \times 10^{7} \mathrm{t}$ and $2.05 \times 10^{6} \mathrm{t}$, respectively, with Henan Province having the highest output, with the thresholds being Shandong, Hebei, Sichuan, and Hunan ${ }^{[9]}$. It estimated that the amount of manure produced by livestock and poultry would surely reach $4.24 \times 10^{9}$ t by $2020^{[10]}$. There is a vast development space using livestock and poultry manure as a raw material for organic fertilizer production.

Meanwhile, fertilization is also the most critical way to regenerate livestock manure. However, compared to the amount of livestock manure produced, the scale of domestic livestock manure organic fertilizer production enterprises is still small, and the operating rate is insufficient ${ }^{[11]}$. By 2013, according to the national soil and fertilizer professional statistics of the National Agricultural Technology Center, the total number of inorganic and organic fertilizer production enterprises has grown from less than 1000 in 2005 to 4103 . The overall design capacity of organic fertilizer has increased from $8.00 \times 10^{6} \mathrm{t}$ in 2005 to $4.70 \times 10^{8} \mathrm{t}$. The actual total production capacity is $2.30 \times 10^{8} \mathrm{t}$, of which 803 with an annual output of more than $2.00 \times 10^{5}$ t for $19.57 \%$ of the scale of enterprises, and 1279 with $0.5 \times 10^{5}-2 \times 10^{5}$ for $31.17 \%$ of the range of enterprises. Refined organic fertilizer enterprises accounted for $72.6 \%$ of the scale of organic fertilizer production enterprises, organic-inorganic compound fertilizers accounted for $19.8 \%$ of volume, and biological organic fertilizers accounted for $7.6 \%$ of the total. At the same time, the regional distribution of internal organic fertilizer production enterprises has reduced and concentrated. Firstly, it distributed in economically developed regions, including Guangdong, Jiangsu, and Fujian. It characterized by good environmental awareness and relatively mature technical support; regions, including Shandong, Hebei, and other regions. The survey results show that organic fertilizer production enterprises in Shandong, Guangdong, Hebei, Jiangsu, and Liaoning account for more than $50 \%$ of the national organic fertilizer production enterprises ${ }^{[12]}$. Following the development of the organic fertilizer industry, due to factors such as high production costs, slow fertilizer efficiency, and high labor intensity, the promotion and application of organic fertilizers have progressed slowly. Farmers are not enthusiastic about using organic fertilizers. Other problems often occur, such as some organic fertilizer companies have overstocked product inventory, low market share, and sales obstacles ${ }^{[13-16]}$.

To better promote organic fertilizer and clarify the issues in the current application, this preliminary study would focus on organic fertilizer production and discuss the entire process from livestock manure-organic fertilizers to farmland applications (Figure 1). Furthermore, this study would also summarize the fertilizer utilization model of livestock and poultry manure, analyze the production and application cost of organic manure sewage and organic fertilizer, and put forward some suggestions for the popularization and application of organic manure in China.

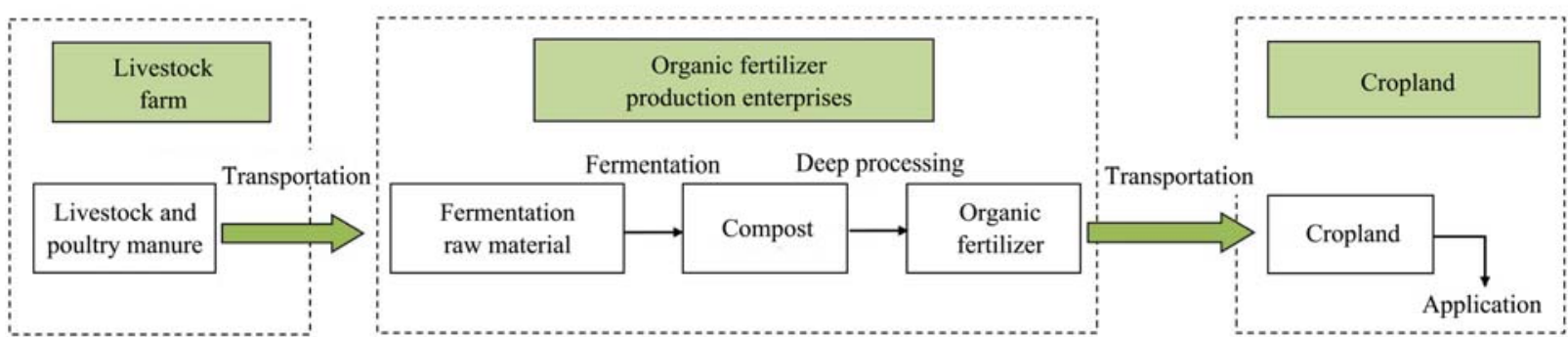

Figure 1 Main link among livestock and poultry manure, organic fertilizer, and field application

\section{Methods}

This study mainly adopts a discussion with enterprises and farmers and questionnaires. The survey period was from March 2017 to May 2018, and the targets were organic fertilizer plants using livestock and poultry manure as raw materials and related farms and organic fertilizers user. The survey contents mainly include the livestock and poultry manure collection and transportation mode, the main costs of each step of the organic fertilizer production process, the alternative methods, and the costs of organic fertilizer.

The exploration scope covers 23 provinces (cities, autonomous regions) and 344 counties, of which covering 96 major livestock counties, including 49 in North China, 22 in East China, 8 in South China, 8 in Central China, 4 in Northwest China, and 5 in Southwest China (Figure 2). The survey questionnaires distributed 374 copies, of which the active recovery of 343 . Of the 343 questionnaires collected from organic fertilizer production enterprises, 80 organic fertilizer plants and breeding farms are the same operating entity, and 263 organic fertilizer plants are third-party agencies that do not rely on breeding farms. We mainly target third party institutional research on the mechanism and cost of integration of manure collection and transportation and organic fertilizer production.

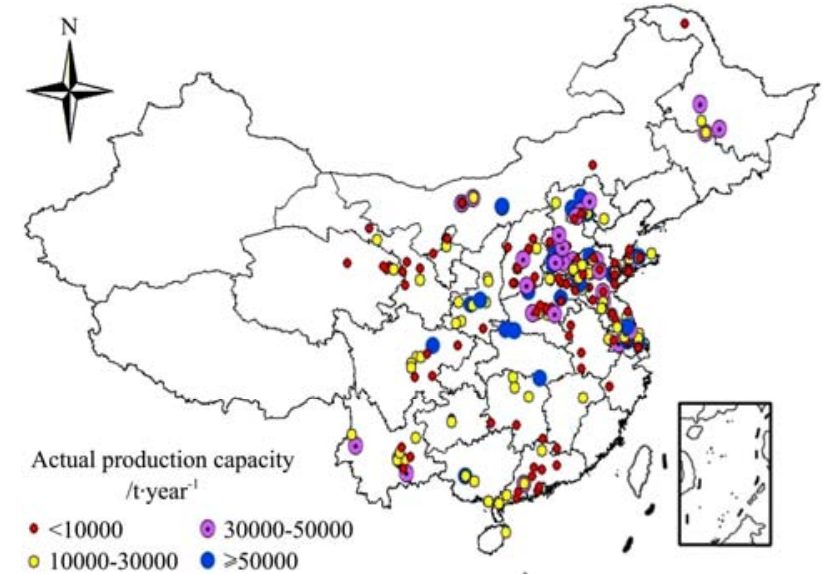

Figure 2 Distribution map of investigated organic fertilizer enterprises nationwide

\section{Results and discussion}

\subsection{Fertilization utilization modes of livestock and poultry manure}

There are three main types of livestock and poultry manure utilization was judging from the investigation currently.

One is that organic farms produce organic fertilizer on their own (Figure 3). This model accounted for $24.02 \%$ of the total 
survey. This method reduces the procurement of manure, the cost of organic fertilizer production, and avoids pollution caused by manure transportation. However, there is a problem of substantial investment in the construction of the farm. For example, the production materials of Beijing Century Dade Environmental Protection Technology Co. Ltd. are all purchased from the breeding farm at the cost of $300 \mathrm{RMB} / \mathrm{t}$ for the production of organic fertilizer and biological organic fertilizer. Among the organic fertilizer enterprises surveyed, this model accounted for more than $90 \%$.

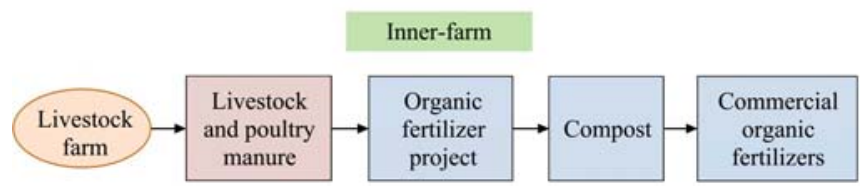

Figure 3 Mode 1: Organic farms produce organic fertilizer on their own

The second is the harmless in-situ treatment of farms and deep third-party processing to produce organic fertilizer (Figure 4). This model accounts for $5.11 \%$ of the total survey. The specific method is that the farm composts livestock and poultry manure in situ to form the first product, and the third-party company purchases the original product and further processes it to produce organic fertilizer. The composting process not only did a harmless treatment but also reduced the water content in the feces ${ }^{[17]}$. This mode can also avoid pollution caused by fecal transportation and minimize transportation costs. For instance, Xincai County China Power Construction Group in Henan Province implemented a fee system for manure treatment. If the manure concentration is $3 \%-8 \%$, it will be treated for free. When the manure concentration is higher than $8 \%$, the price is 30 $40 \mathrm{RMB} / \mathrm{t}$. A certain processing fee also will be charged if the manure concentration is lower than 3\%. Similar to this, Anping County in Hebei Province relies on Yufeng Jingan Company to implement centralized treatment of pig manure, and the manure concentration at $3 \%-8 \%$ is for free. If the concentration is higher than $8 \%$, the price is $40-80 \mathrm{RMB} / \mathrm{t}$. When the concentration is less than $3 \%$, a processing fee will be charged for $20 \mathrm{RMB} / \mathrm{t}$.

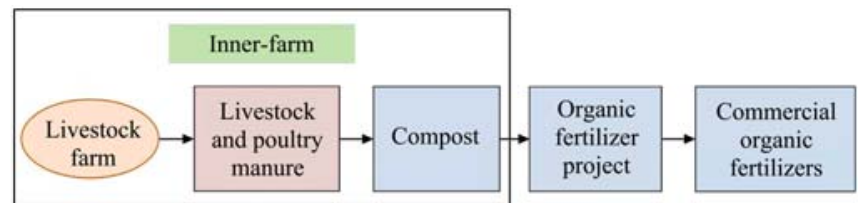

Figure 4 Mode 2: Harmless in-situ treatment of farms and deep third-party processing to produce organic fertilizer

The third one is using third parties to collect animal manure to produce organic fertilizer (Figure 5). This model accounts for $70.87 \%$ of the total survey. The specific method is that third-party companies purchase animal manure and focus on the production of organic fertilizer. This model mechanism is flexible, but fecal transportation is easy to cause pollution, which also increases raw material purchase and transportation costs. Shuangcheng Dimeng Biotechnology Co. Ltd. in Heilongjiang Province provided integrated processing equipment for farms and promoted the operation mode of organic fertilizer exchange for primary fertilizer. Every $5 \mathrm{t}$ of primary fertilizer collected in the farm is exchanged for $1 \mathrm{t}$ of commercial organic fertilizer. Waterway Ecological Technology Co., Ltd. in Chongqing Province invested in the establishment of waste treatment facilities in large-scale farms to solve the waste pollution of the farms, and obtained raw materials for free.

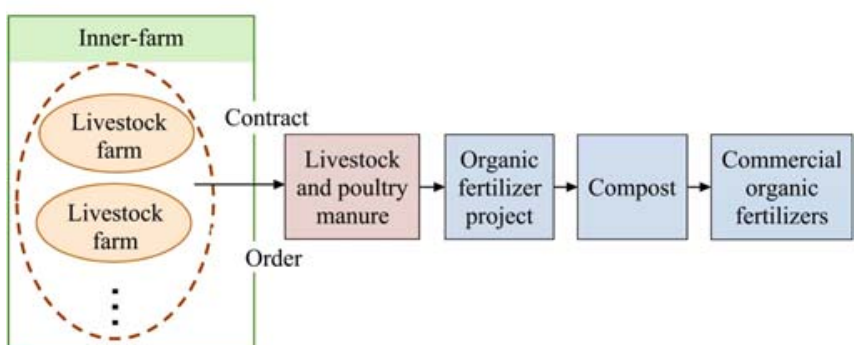

Figure 5 Mode 3: Third parties collect animal manure to produce organic fertilizer

Of the above three collection modes, the first one accounts for the vast majority, and the mechanism is simple and easy to operate. The second collection mode judges whether to collect fees or pay according to the concentration of fecal sewage, which can better reflect the environmental protection contribution of organic fertilizer plants and help increase the enthusiasm of natural fertilizer plants. The third collection mode places integrated processing equipment on the farm. Processing primary fertilizer products before transportation help reduce long-distance transport of livestock and poultry manure and reduce environmental pollution. Besides, the manure charging model and the provision of integrated equipment models are more suitable for small and medium-scale farms. It is recommended to promote the use of manure resources in the entire county to help solve the problem of low and medium-scale manure pollution.

\subsection{Analysis of organic fertilizer production cost}

Organic fertilizer is one of the leading products of natural fertilizer plants. It is mainly commercial organic fertilizer formed by composting products through further processing and granulation $^{[18]}$. The survey found that $65.01 \%$ of organic fertilizer plants mainly produce commercial organic fertilizer.

Based on the three modes, we analyzed the cost of organic fertilizer production, respectively (Figure 6). Like the first one, the farm produces organic fertilizer on its own, the total price is $500.3 \mathrm{RMB} / \mathrm{t}$, of which the purchase cost of auxiliary materials (mainly including straw, wood chips) is $228.6 \mathrm{RMB} / \mathrm{t}$, accounting for $45.69 \%$; the transportation cost of supplemental materials is $56.8 \mathrm{RMB} / \mathrm{t}$, accounting for $11.36 \%$; the cost of fuel power is $124.6 / t$, accounting for $24.9 \%$; selling expenses of $90.3 \mathrm{RMB} / \mathrm{t}$, accounting for $18.05 \%$. Other than that, there is the harmless in-situ treatment of farms and deep third-party processing to produce organic fertilizer. The total cost is $645.0 \mathrm{RMB} / \mathrm{t}$, of which the primary product purchase cost is $331.7 \mathrm{RMB} / \mathrm{t}$, accounting for $51.42 \%$; the primary product transportation cost is $46.7 \mathrm{RMB} / \mathrm{t}$, accounting for $7.24 \%$; the fuel power cost is $163.3 \mathrm{RMB} / \mathrm{t}$, accounting for the ratio is $25.32 \%$; the selling expense is $103.3 \mathrm{RMB} / \mathrm{t}$, accounting for $16.02 \%$. Besides, there is another way to use third parties to collect animal manure to produce organic fertilizer. The total cost is $696.9 \mathrm{RMB} / \mathrm{t}$, of which the purchase cost of raw materials and auxiliary materials is $338.3 \mathrm{RMB} / \mathrm{t}$, accounting for $48.54 \%$; the transportation cost of raw materials and supplemental materials is $100.7 \mathrm{RMB} / \mathrm{t}$, accounting for $14.45 \%$; the cost of fuel power is $141.7 \mathrm{RMB} / \mathrm{t}$, considering for it is $20.33 \%$; the selling expense is $116.2 \mathrm{RMB} / \mathrm{t}$, accounting for $16.68 \%$. From the results, it showed that the third mode has the highest, followed by the second mode and the first mode has the lowest production cost. 


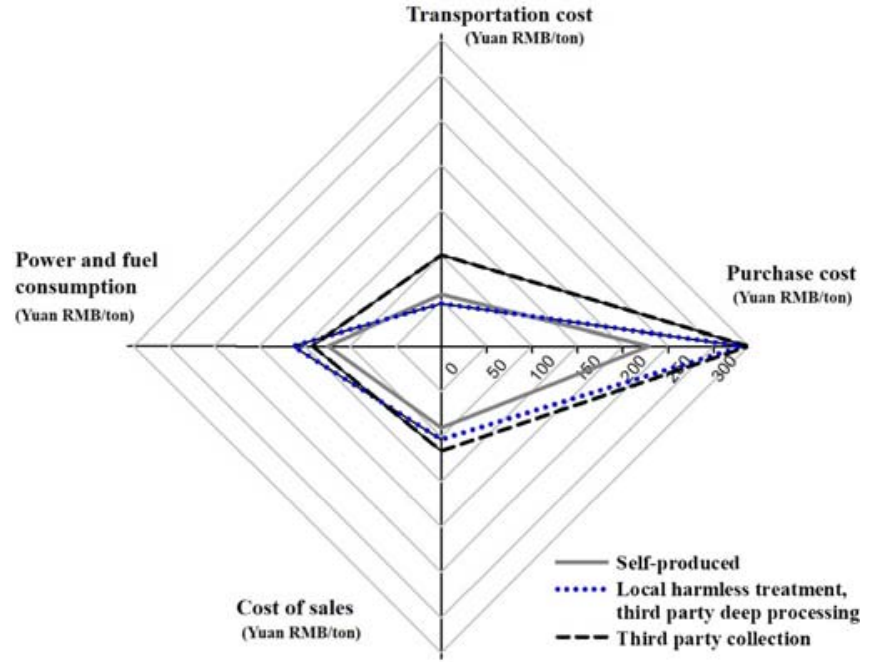

Figure 6 Cost analysis of producing organic fertilizer

\subsection{Analysis of compost production cost}

Compost is another one of the leading products of organic fertilizer plants. It is mainly a powdered fertilizer product formed by aerobic fermentation of raw materials such as livestock manure $^{[19]}$. 34.99\% of natural fertilizer plants mainly produce compost products.

Similarly, we analyzed the cost of compost production in three modes (Figure 7). The first mode that the farm produces organic fertilizer on its own, the total price is $415.195 \mathrm{RMB} / \mathrm{t}$, of which the purchase cost of auxiliary materials (mainly including straw, wood chips) is $198.6 \mathrm{RMB} / \mathrm{t}$, accounting for $47.83 \%$; the transportation cost of supplemental materials is $46.92 \mathrm{RMB} / \mathrm{t}$, accounting for $11.30 \%$; the cost of fuel power is $80.99 /$ t, accounting for $19.51 \%$; selling expenses of $88.7 \mathrm{RMB} / \mathrm{t}$, accounting for $21.36 \%$. Secondly, there is the harmless in-situ treatment of farms and deep third-party processing to produce organic fertilizer. The total cost is $539.25 \mathrm{RMB} / \mathrm{t}$, of which the primary product purchase cost is $315.6 \mathrm{RMB} / \mathrm{t}$, accounting for $58.53 \%$; the primary product transportation cost is $40.4 \mathrm{RMB} / \mathrm{t}$, accounting for $7.48 \%$; the fuel power cost is $106.2 \mathrm{RMB} / \mathrm{t}$, accounting for the ratio is $19.68 \%$; the selling expense is $97.2 \mathrm{RMB} / \mathrm{t}$, accounting for $18.01 \%$. Another way is using third parties to collect animal manure to produce organic fertilizer. The total cost is $623.0 \mathrm{RMB} / \mathrm{t}$, of which the purchase cost of raw materials and auxiliary materials is $319.9 \mathrm{RMB} / \mathrm{t}$, accounting for $51.35 \%$; the transportation cost of raw materials and supplemental materials is $95.5 \mathrm{RMB} / \mathrm{t}$, accounting for $15.32 \%$; the cost of fuel power is $92.1 \mathrm{RMB} / \mathrm{t}$, considering for it is $14.78 \%$; the selling expense is $115.53 \mathrm{RMB} / \mathrm{t}$, accounting for $18.54 \%$. Like organic production cost, for compost production, the third mode has the highest production cost, followed by the second mode and the third one with the lowest. Compared with the production cost of organic fertilizer, the production cost of compost is relatively small, which is because that the organic fertilizer requires higher physical and chemical characteristics such as livestock manure and the accumulation rate of raw materials of straw, and the oil and electricity consumed during processing is more elevated.

\subsection{Application cost analysis between organic fertilizer and chemical fertilizer}

In addition to production costs, we also analyzed the application costs when using organic and chemical fertilizers on different crops (corn, vegetables, apples) based on three models (Figure 8). At present, there is little analysis and research on the cost of using organic fertilizers. The fertilizer application data source in the calculation process is from the 'National Agricultural Product Cost-Effective Data Collection 2017 ${ }^{,[20]}$. The application cost mainly refers to the expenditure of farmers in applying organic fertilizer in the field, including organic fertilizer transportation and field application costs.

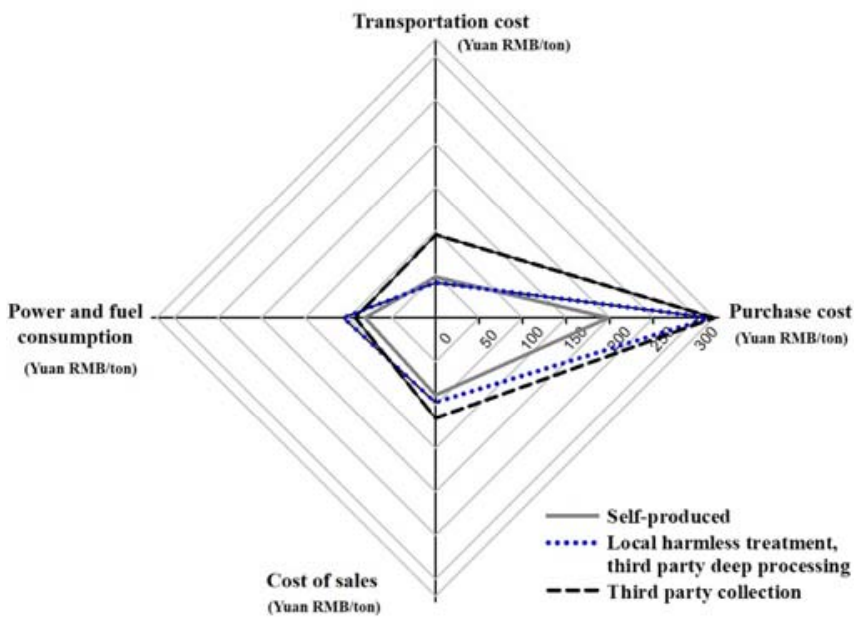

Figure 7 Cost analysis of producing compost fertilizer

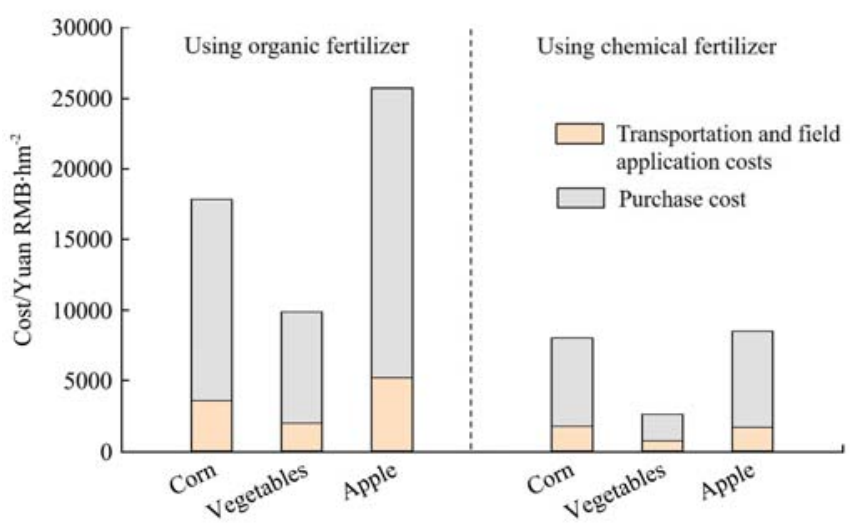

Figure 8 Application cost of organic fertilizer and chemical fertilizer

It can be seen from the results that the average price of organic fertilizer applied to corn, vegetables and apple crops are $9.91 \times 10^{3} \mathrm{RMB} / \mathrm{hm}^{2}, 1.78 \times 10^{4} \mathrm{RMB} / \mathrm{hm}^{2}$ and $2.56 \times 10^{4} \mathrm{RMB} / \mathrm{hm}^{2}$, respectively. By contrast, the average cost of chemical fertilizers are $8.07 \times 10^{3} \mathrm{RMB} / \mathrm{hm}^{2}, 2.64 \times 10^{3} \mathrm{RMB} / \mathrm{hm}^{2}$, and $8.54 \times 10^{3} \mathrm{RMB} / \mathrm{hm}^{2}$, respectively. The results showed that the application cost per unit area of organic fertilizer was significantly higher than that of chemical fertilizer, among the application cost, which was consistent with results obtained by Liu et al. ${ }^{[21]}$ Especially the raw material cost occupies a higher proportion of the application cost, whether using organic or chemical fertilizers. At the same time, it can be found that, for all three crops, the costs of transportation and field applications occupy a higher expense of using organic fertilizers when compared with using chemical fertilizers per unit area. The reasons for the high price of organic fertilizers are mainly because the artificial organic fertilizers are currently employed, and there is no dedicated fertilizer application equipment, as the cost of labor continues to increase, the cost of organic fertilizers also increases ${ }^{[22]}$. Besides, compared with chemical fertilizers, organic fertilizers made from livestock and poultry manure generally have lower nitrogen and phosphorus contents than chemical fertilizers. Still, their bulk density is relatively small, while their quantity and quality are relatively 
$\operatorname{larg} e^{[23,24]}$. It results in higher transportation costs for organic fertilizer fields.

\section{Conclusions}

4.1 Promoting suitable fertilizer manure utilization models for livestock and poultry

Among the three fertilizer and utilization modes of livestock and poultry manure, the way of self-producing organic fertilizer by the farm, which can treat livestock and poultry manure in situ, can effectively avoid pollution caused by transportation and reduce production costs. It is recommended that large and medium-sized farms be promoted. While, for small-scale farms, the mode of harmless in-situ treatment and deep third-party processing of organic fertilizers can be adopted. It can also avoid pollution caused by transportation, and benefit the scale benefits brought by the concentrated production of organic fertilizers. Promoting according to the actual situation will be suggested.

\subsection{Organic fertilizer subsidy policy}

To encourage the production and application of organic fertilizer, it is recommended that the central government establish a special subsidy fund for organic fertilizer. From the production side, it is recommended to focus on subsidizing farms that produce organic fertilizer on their own. Each ton of organic fertilizer can be supported at $50 \%$ to $60 \%$ of the total production cost, which is a subsidy of about $300 \mathrm{RMB} / \mathrm{t}$, which can effectively reduce breeding and the burden of organic fertilizer production in the field. From the demand side, allowances can be subsidized according to the principle that the application costs after subsidies are the same as the cost of chemical fertilizers, which is about $500 \mathrm{RMB} / \mathrm{hm}^{2}$. To motivate farmers using organic fertilizers, it is recommended to subsidize farmers directly. Green fertilizer subsidies can be piloted in counties where livestock manure resources are utilized.

\subsection{Increasing scientific and technological research and} development of fertilizers for livestock manure

At present, livestock and poultry manure fertilizer utilization technology innovation and engineering integration in China are still unable to meet the actual needs. Livestock and poultry manure in-situ rapid composting technology and equipment are still lacking. The organic combination of organic fertilizer application machinery and agronomic technology is not close enough. Mechanism and technical research are also obviously insufficient. It is recommended to set up a unique R\&D plan for the utilization of livestock manure waste resources, organize relevant scientific research institutions in the industry to strengthen scientific and technological research for the usage of livestock manure.

\section{Acknowledgements}

This work was supported by the National Key R \& D Program of China (2017YFD0800800).

\section{[References]}

[1] Senesi N. Composted materials as organic fertilizers. Science of the Total Environment, 1989; 81-82: 521-542.

[2] Wang S Q, Si Y B, Chen H M. Review and prospects of soil environmental protection in China. Soils, 1999; 31(5): 255-260.

[3] Lu Y L, Chadwick D, Norse D, Powlsond D, Shi W M. Sustainable intensification of China's agriculture: The key role of nutrient management and climate change mitigation and adaptation. Agriculture, Ecosystems \& Environment, 2015; 209: 1-4.

[4] Zhang M, Li B, Xiong Z Q. Effects of organic fertilizer on net global warming potential under an intensively managed vegetable field in southeastern China: A three-year field study. Atmospheric Environment, 2016; 145: 92-103.

[5] Forge T, Kenney E, Hashimoto N, Neilsen D, Zebarth B. Compost and poultry manure as preplant soil amendments for red raspberry: Comparative effects on root lesion nematodes, soil quality and risk of nitrate leaching agriculture. Agriculture, Ecosystems \& Environment, 2016; 223: 48-58.

[6] Gao Y H, Li Y, Sun M, Zhang Y P. Utilization situation and technical analysis of organic wastes agricultural use in Shandong Province. Shandong Agricultural Sciences, 2011; 7: 98-101. (in Chinese)

[7] Ministry of Agriculture of the People's Republic of China. Action plan for zero growth of fertilizer use by 2020. 2015. http://www.moa.gov.cn/ nybgb/2015/san/201711/t20171129_5923401.htm (in Chinese)

[8] Niu X X, Ju X T. Organic fertilizer resources and utilization in China. Journal of Plant Nutrition and Fertilizer, 2017; 23(6): 1462-1479.

[9] Li H, Feng W T, He X H, Zhu P, Gao H J, Sun N, et al. Chemical fertilizers could be completely replaced by manure to maintain high maize yield and soil organic carbon (SOC) when SOC reaches a threshold in the Northeast China Plain. Journal of Integrative Agriculture, 2017; 16(4): 937-946.

[10] Wu S X, Liu H B, Huang H K, Lei Q L, Wang H Y, Zhai L M, et al. Analysis on the amount and utilization of manure in livestock and poultry breeding in China. Strategic Study of CAE, 2018; 20(5): 103-111.

[11] Fu C H, Shan G F. Development of organic fertilizer industry in China and market outlook. Fertilizer Industry, 2017; 44(1): 9-12, 30. (in Chinese)

[12] Zhu F L, Ma Y H, Zhou J, Guan J, Liang J N, Zhao Y P. Analysis on present situation of pollution and utilization of animal excrement in China. Anhui Agricultural Science Bulletin, 2008; 14(13): 48-50. (in Chinese)

[13] Ma C B. Present state and perspective of organic fertilizer industrialization in China. Phosphate \& Compound Fertilizer, 2004; 19(1): 9-13.

[14] Yang F, Ma C B. General situation, problem, counter-measurements and the prospects of the organic fertilizer's industrialization. Humic Acid, 2006; 2: 18-23, 37. (in Chinese)

[15] Yang F, Li R, Cui Y, Duan Y H. Utilization and develop strategy of organic fertilizer resources in China. Soil and Fertilizer Sciences in China, 2010; 4: 77-82.

[16] Liu S J, Xue W T, Miao W Y, Sun H, Wu R, et al. Characteristics and development trend of organic fertilizer industry. Vegetables, 2018; 12: 26-29.

[17] Han S Q, Li J L, Zhou Q, Liu G F, Wang T. Harmless disposal and resource utilization of wastes from the lake in China: Dewatering, composting and safety evaluation of fertilizer. Algal Research, 2019; 43, 101623.

[18] Mishra D J, Singh R, Mishra U K, Shahi S K. Role of bio-fertilizer in organic agriculture: A review. Research Journal of Recent Science, 2013(2): 39-41.

[19] Li J, Peng S P. Practical handbook of compost engineering. Beijing, Chemical Industry Press, 2011. (in Chinese)

[20] National Development and Reform Commission. National agricultural product cost benefit. Beijing, China Statistics Press, 2017. (in Chinese)

[21] Liu H T, Chen T B, Zheng G D. Comparative analysis of organic and chemical fertilizer production energy consumption, input cost and environmental benefit: Sewage sludge composting as example. Ecology and Environmental Sciences, 2010; 19(4): 1000-1003.

[22] Wang H, Wang Q. A theoretical analysis on the optimal scale of livestock farm: A perspective of pollution controlling. Resources and Environment in the Yangtze Basin, 2011; 20(5): 622-627. (in Chinese)

[23] Zeng Y, Hong H S, Cao W Z, Chen N W, Wang W P. Economic analysis on uses of livestock manure on cropland. Journal of Xiamen University (Natural Science), 2004; 43(B08): 195-200. (in Chinese)

[24] Zheng J, Wang B. Research on development bottleneck of commercial organic fertilizer in China. Environment and Sustainable Development, 2017; 42(3): 38-41. 